\title{
Improvement of ATIS Model Performance under Connected Vehicle Environment
}

\author{
김 회 경* \\ (Hoe Kyoung Kim)
}

\section{요 약}

본 논문은 최근 지능형교통시스템에서 중요한 수단으로 간주되고 있는 차량 간 통신을 이용한 분산식 첨단 교통정보 시스템을 개발하고자 한다. 또한 독립자동유고감지 기능을 통해서 제안된 첨단 교통정보시스템의 효과를 개선하고자 한 다. 이상적인 통신 환경을 가정한 단순화된 교통네트워크에서 미시적 시뮬레이션 모델인 VISSIM을 통해 제안된 첨단 교 통정보시스템을 구현하였으며 특히 비반복적으로 일어나는 교통상황(예를 들면, 교통사고)을 사용하여 모델의 효과를 관 찰하였다. 결론적으로 본 연구에서는 차량 간 통신을 통한 첨단 교통정보시스템의 효율성을 확인함과 동시에 독립자동 유고감지 기능이 시스템의 성능을 향상시키는 것을 보여주고 있다.

\begin{abstract}
This paper develops a decentralized advanced traveler information system (ATIS) under the connected vehicle environment, recently regarded as one of most promising tools in Intelligent Transportation Systems (ITS). The performance of the proposed ATIS is reinforced by introducing autonomous automatic incident detection (AAID) function. The proposed ATIS is implemented and tested using an off-the-shelf microscopic simulation model (VISSIM) on a simple traffic network under idealized communication conditions. A key attribute of this experiment is the inclusion of a non-recurrent traffic state (i.e., traffic incident). Simulation results indicate that the ATIS using V2V communication is efficient in saving drivers' travel time and AAID plays an important role in improving the effectiveness of the system.
\end{abstract}

Key words: Advanced Traveler Information System (ATIS), Vehicle-to-Vehicle (V2V) Communication, Dynamic Route Guidance System (DRGS), Automatic Incident Detection (AID) Algorithm, Dynamic Traffic Assignment (DTA)

\section{I . Introduction}

Over the past several decades, Intelligent Transportation Systems (ITS) have emerged as a promising means to address traffic congestion and improve traffic mobility. ITS can reduce the need for new, often costly, construction by increasing existing traffic system efficiency. ITS also may be utilized to enhance the existing infrastructure through accurate traffic state monitoring, alternative traffic strategy computation and implementation, and up-to-date distribution of traffic information to drivers. More recently, decreasing wireless communication costs has led to significant exploration of wireless ITS solutions. Enabled by wireless communication with the surrounding infrastructure or neighboring instrumented vehicles each instrumented

\footnotetext{
* 주저자 및 교신저자 : 동아대학교 도시계획학과 조교수

† 논문접수일 : 2012년 2월 21일

† 논문심사일 : 2012년 7월 24일

† 게재확정일 : 2012년 8월 14일
} 
vehicle may act as a real time traffic data collector and provider (e.g., link travel time in this paper) as well as a traffic information consumer. For example, the Vehicle-to-Vehicle (V2V) communication system is one platform of $\mathrm{V} 2 \mathrm{X}$ modes encompassing all types of transportation-related communication systems such as Vehicle-to-Infrastructure (V2I), V2V, and Vehicle-toPedestrian (V2P) and implementing connected vehicle technology to improve the traffic safety, mobility, and energy-efficiency [1, 2].

A Dynamic Route Guidance System (DRGS) is an effective and practical ATIS application that can use the connected vehicle technology. DRGS attempts to search for the most cost-effective route (normally measured in terms of travel time) from the origin to the destination for participating vehicles. Typical DRGS examples include simulation-based Dynamic Traffic Assignment (DTA) systems (e.g., DynaMIT and DynaSmart) [3, 4]. Using internal driver behavior models such systems are capable of estimating and predicting the traffic state based on various on-line traffic data and determining optimal routes (i.e., user equilibrium or system optimal) consistent with future traffic states. However, large network DTA models operated in traffic centers (i.e., centralized DTA (CDTA)) demand significant computational resources and predictive input information, leading to nontrivial time lags between a non-recurrent traffic event occurrence and a responsive traffic strategy [5-7]. Hawas and Mahmassani [5] proposed a decentralized DTA (DDTA) which is spatially distributed and more frequently updates vehicle routes, relying on limited and locally available traffic information. Chiu and Mahmassani [6, 7] developed a hybrid DTA (HDTA) interplaying between a CDTA and a DDTA. They concluded that DDTA and HDTA are more robust under incident conditions than CDTA. They also stressed that demand prediction is highly sensitive to inaccurate data and stochasticity in driver behavior.
ATIS using V2V communication, operated in the decentralized fashion, can be a counterpart of DTA. Much of the research on ATIS using V2V communication has focused on the underlying model development $[8,9]$ or investigation of system-wide sensitivity to traffic flow, penetration ratio, and communication radio range [10, 11]. Challenges such as early non-recurrent traffic event detection, data accuracy, and reflecting driver response to information, commonly addressed issues in DTA research [6, 7, 12], have not been as widely explored in the ATIS using V2V communication environment.

This paper briefly introduces a dynamic ATIS framework using V2V communication, developed in the author's other papers [13-16], consisting of several key modules (i.e., vehicle communication, ITS database management process, dynamic routing process, and autonomous automatic incident detection), which are directly integrated into an off-the-shelf microscopic simulation model. The ATIS model performance is investigated on a simple experimental traffic network to understand the basic operational characteristics of the approach and explore the feasibility of the integration of such ATIS architecture in DTA system. Future investigations will provide more in depth analysis, exploring the different facets of the architecture on a larger traffic network. This research helps establish a basic understanding ATIS using V2V communication, hopefully informing future operational methodology development and increasing their prospect of successful field deployment.

\section{Model Development and Operation Methodology}

This paper builds on earlier efforts [13-16] to develop a framework for an ATIS model using V2V communication by directly integrating a communication modeling capability into a transportation microscopic 
simulation model, VISSIM. VISSIM also offers possibilities to access and control most objects available with itself to elicit data from vehicles, to save output periodically, to change the vehicle behavior rules, and to automate necessary tasks at runtime $[17,18]$. The brief description of the development process of the proposed ATIS model is provided below and see [13-16] for the further explanation.

\section{Basic ATIS Model Using V2V Communication}

The framework consists of three primary components: vehicle communication, on-board database management, and dynamic re-routing. The current communication model assumes an idealized communication environment, in that the communication signal is not interrupted and no data is lost during communication. The communication model consists of two primary elements; identification of interconnected groups of participating vehicles (communication group formation process) and data propagation within an interconnected group (data dissemination process). Currently, it is assumed that a communication protocol similar to broadcasting with flooding would be utilized in a field implementation, where data communication is conducted within an interconnected group of vehicles without direct consideration of communication routing issues [19]. The former process is accomplished via an algorithm developed to form communication groups composed of individual participating vehicles within single or multi-hop data communication range in the current communication time interval. After communication groups are formed data may then be disseminated among vehicles within a group. In the current data dissemination the travel time data stored on each vehicle (which includes the travel time data for that vehicle as well as travel time data from other vehicles shared with that vehicle in previous communication time interval) is shared among all vehicles in the communication group.

Also, to make a routing decision each participating vehicle must estimate their expected travel time over their current route and all possible alternative routes. To accomplish this task the vehicles must first estimate the travel time over each network link. An on-board estimated link travel time update process is executed every system update time interval. An estimated link travel time is the average of the travel time aggregated over the current time bin and the three previous bins. Then, based on the estimated traffic state information participating vehicles calculate the travel time from their current location to their destination every system update time interval. If an alternate route is estimated to reduce the vehicle travel time relative to its current route, drivers switch to the new route.

\section{Enhanced ATIS Model Using V2V Communication}

This paper incorporates a complementary function (i.e., an Autonomous Automatic Incident Detection algorithm, AAID) into the basic ATIS model to improve the system efficiency and reliability that could be deteriorated due to delayed detection of non-recurrent traffic congestion.

The AAID implemented in this paper autonomously detects local non-recurrent traffic states by utilizing the elapsed time of a participating vehicle on a link. This is a significant departure from approaches found in fixed infrastructure traffic information systems that commonly use upstream and downstream traffic measures of volume, speed, and occupancy [20]. In the proposed AAID each participating vehicle acts as an independent incident detection probe. If the elapsed time on a link is greater than a pre-defined time criterion, the vehicle will issue and disseminate a 
congestion alert to neighboring vehicles. The congestion alert is given in the form of a travel time several orders of magnitude greater than the historic travel time. Vehicles receiving congestion information update their route instantly, not waiting for the next system update time interval.

\section{Experimental Design}

This paper utilizes a simple VISSIM traffic network, as seen in <Fig. 1>. All links are one-way with vehicles entering at the leftmost network node and exiting at the rightmost network node. Vehicles are generated at the Vehicle Entry at a constant headway, according to the desired traffic flow rate. Vehicles enter with a desired speed of $48 \mathrm{kph}$. Each generated vehicle is randomly assigned as a participating or non-participating vehicle based on the desired participation rate (i.e., penetration ratio). Upon entering the network each vehicle is assigned an initial route through the network. Two routes are possible; upper route (Link $1 \rightarrow$ Link $2 \rightarrow$ Link $4 \rightarrow$ Link 6) or lower route (Link $1 \rightarrow$ Link $3 \rightarrow$ Link $5 \rightarrow$ Link 6 ). The non-congested travel time of the two routes is approximately equal at $274 \mathrm{sec}$. The departing link (Link 6) is a two-lane road minimizing possible vehicle conflicts at the Link 4/Link 5 merge. Also, the length of the entering link (Link 1) is set to guarantee that full system update time interval (i.e., 3 minutes) will pass while the vehicle is on the link, ensuring that a participating vehicle will undertake the route choice decision process at least once prior to the Final Route Decision Point at the Link 2/Link 3 diverge. To examine the performance of the proposed ATIS models under various traffic states a Traffic Incident is modeled on link 5, from $1000 \mathrm{sec}$ to $2000 \mathrm{sec}$, with one vehicle release every 90 seconds. Each simulation experiment is run for $3600 \mathrm{sec}$, with the reported results the average of ten replicates.

The sensitivity of ATIS models to three underlying factors, namely traffic flow rate, communication radio range, and penetration ratio, are explored in these experiments. Modeled traffic flow rates are $300 \mathrm{vph}$, $514 \mathrm{vph}$, and 720vph, using constant vehicle headways of $12 \mathrm{sec}, 7 \mathrm{sec}$, and $5 \mathrm{sec}$, respectively. Communication radio ranges of $250 \mathrm{~m}, 375 \mathrm{~m}, 500 \mathrm{~m}$, and $625 \mathrm{~m}$ with omni-directional signal emission and no signal interference are tested. Finally, the penetration ratio ranges from $20 \%$ to $100 \%$ in $20 \%$ increment. Average saved travel time is calculated as the difference between the average travel time under the given ATIS scenario and a non-ATIS base model, respectively.

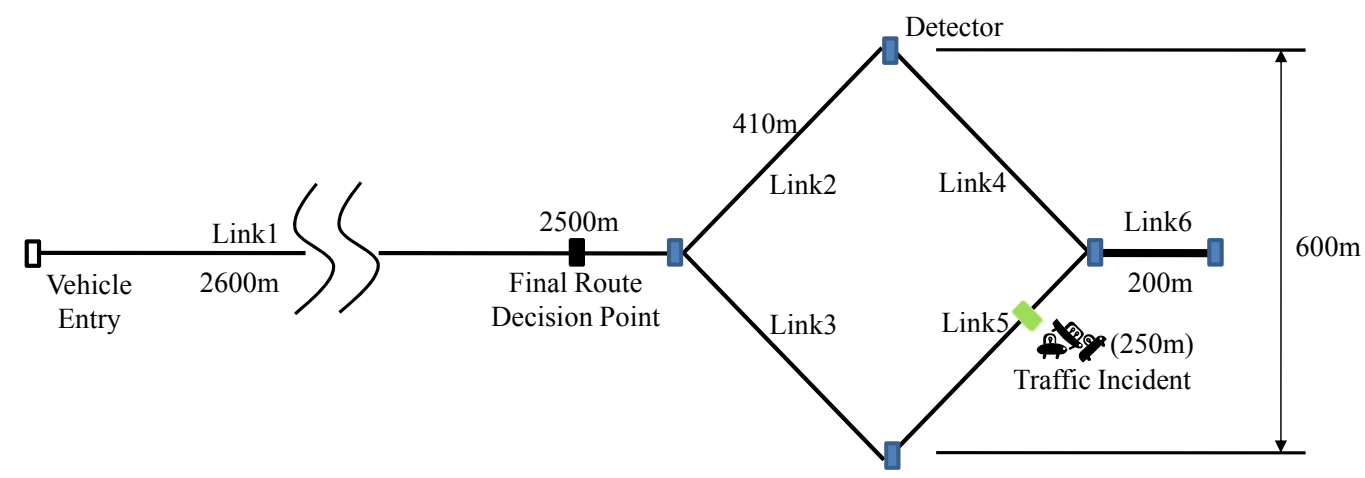

〈Fig. 1〉 Layout of Experimental Traffic Network

Note: the detectors represent check points of the likely coordinates in the digital map to indicate the end of link and to record its link travel time, not the intended as in-field detection devices. 
The default value of user-defined congestion factor employed in AAID function is set to 3 in a desire to balance the timely update of the traffic incident while limiting false alarms. That is, the low factor values would be too sensitive to the insignificant traffic state variations, resulting in too many traffic alerts (i.e., false alarms) and also too high values will delay the timely update of the adverse traffic states [14].

Also, since this study is conducted on the experimental traffic network under ideal communication environment to investigate system performance improvement the simulation calibration and validation processes are not performed this time, but as the penetration ratio increases more practical research circumstance will be formed soon.

\section{Results and Analysis}

\section{Basic ATIS Model}

$<$ Fig. 2> compares average saved travel time per participating vehicle in the Basic ATIS Model under varying communication radio ranges and penetration ratios for 300vph. These results exemplify the behavior seen for the basic ATIS utilizing V2V communication. The primary time savings in all alternatives derived from the identification of the incident condition by the ATIS and the re-routing of

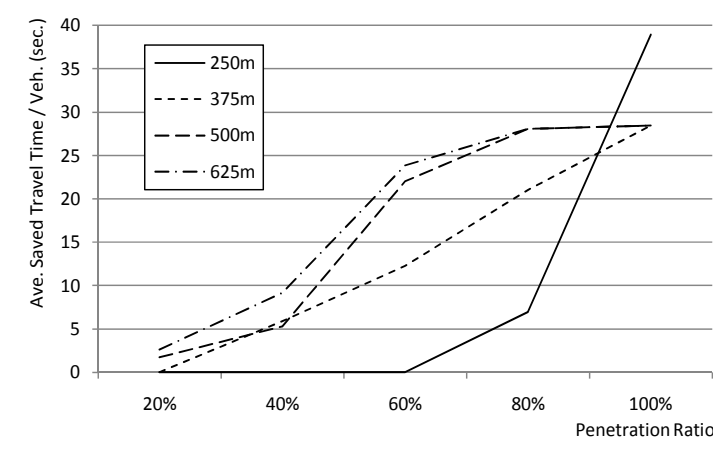

〈Fig. 2〉 Saved Travel Time Comparison in the Basic ATIS Model participating vehicles from the incident route (i.e., lower route) to the non-incident route (i.e., upper route). Intuitively, it may be expected that as radio range and penetration ratio increase the travel time savings would increase as well. This intuition is supported except at the highest penetration ratios.

Interestingly, <Fig. 2> indicates that under the $250 \mathrm{~m}$ radio range more travel time is saved at $100 \%$ penetration ratio than in other longer radio range scenarios. This behavior is due to a bias in the simulation replicate runs, with the upper route tending to have a slightly higher travel time than the lower route (in six of ten runs) before the incident. After the incident has occurred, but prior to the ATIS by V2V communication successfully passing the incident warning upstream, several vehicles may be routed from the upper (non-incident route) to the lower (incident route) for an attempted travel time savings on the order of several seconds. However, the re-routing of these vehicles results in their having a significant longer travel time due to the incident. Only the $250 \mathrm{~m}$ radio range scenario is unaffected. In this scenario the $250 \mathrm{~m}$ range does not allow for efficient message hopping between vehicles because vehicles diverge to link 2 and link 3 at headway of $320 \mathrm{~m}$. In this particular instance the inefficiency of the $250 \mathrm{~m}$ system prevents vehicles from incorrectly routing to the incident route, resulting in higher overall delay savings. While these particular results are function of the network and given replicate trials an important issue is raised. In such an ATIS using V2V communication it is possible to re-route a vehicle onto a worse route than their current one due to a time lag in receiving incident data, particularly when vehicles re-route for small travel time savings within a normal (non-incident) variability.

\section{Investigation of Incident Detection}

$<$ Fig. 3> depicts vehicle travel time for each vehicle 


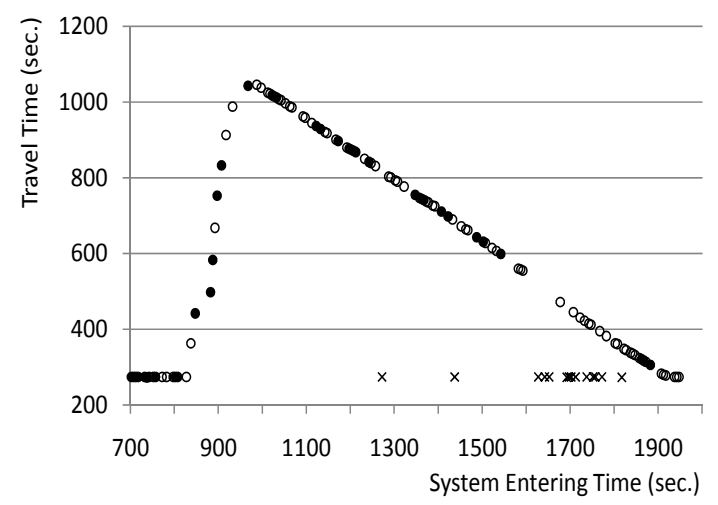

(a) Basic ATIS (375m)

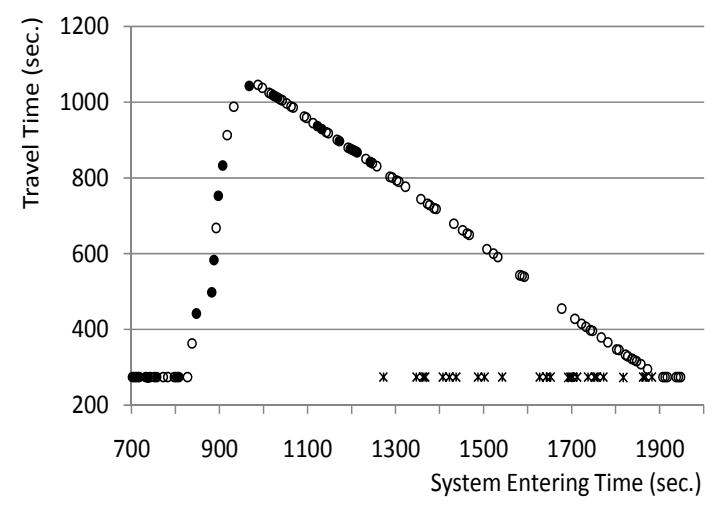

(c) Basic ATIS (625m)

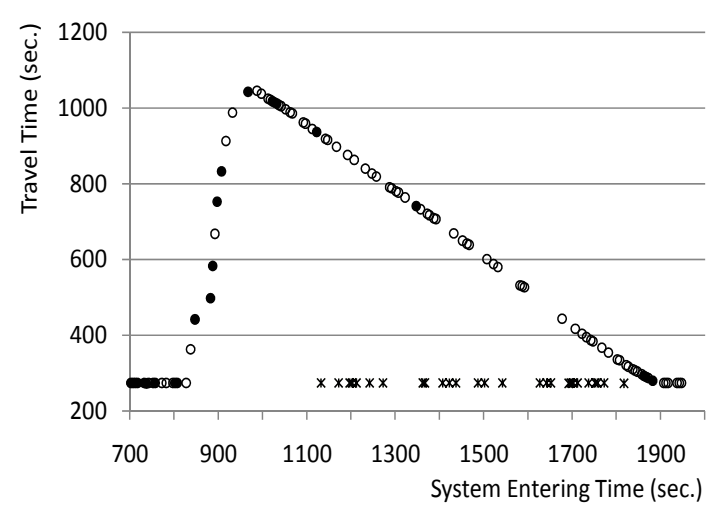

(b) Enhanced ATIS (375m)

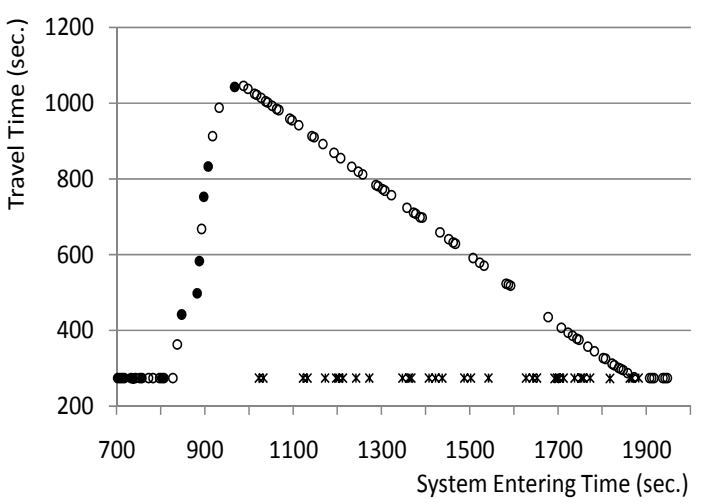

(d) Enhanced ATIS (625m)

〈Fig. 3〉 Individual Vehicle Re-routing Pattern Comparison (720vph, 40\% Penetration Ratio, and 5th Run) Notes: black dot $=$ participating vehicles, white dot $=$ non-participating vehicles

$x=$ participating vehicles re-routing from the lower to the upper route

assigned to the lower route upon entering the system. For this analysis the vehicle's travel time through the system (y-axis) is plotted relative to its system entering time (x-axis) which means the time vehicles enter the network. The four plotted scenarios highlight the impact in the lag between an incident and the detection and passing of the incident data upstream. <Fig. 3> (a) plots the basic framework with a radio range of $375 \mathrm{~m}, \quad<$ Fig. 3> (b) plots the basic framework, incorporating AAID, at a radio range of $375 \mathrm{~m}$, and $<$ Fig. 3> (c) and <Fig. 3> (d) are the same as $<$ Fig. 3> (a) and <Fig. 3> (b), except for utilizing a radio range of $625 \mathrm{~m}$. The plotted results are for $720 \mathrm{vph}, 40 \%$ penetration ratio, and a representative replicate trial. Also, <Table 1> shows the ATIS performance comparison in terms of number of vehicles re-routing from the lower route to the upper route, average travel time savings of incident-involved participating vehicles, and average travel time savings of all participating vehicles.

In <Fig. 3> (a) (Basic ATIS Model with 375m radio range) it is seen that immediately after the traffic incident occurs participating vehicles (indicated by a black dot) continued to enter the lower route and as a result were delayed due to the incident. These vehicles do not re-route to the non-incident route due to the time delay in receiving the incident warning. $<$ Fig. 3> (b) indicates the re-routing pattern when 
〈Table 1〉 ATIS Performance Comparison

\begin{tabular}{c|c|c|c}
\hline & $(1)$ & $(2)$ & $(3)$ \\
\hline Basic ATIS $(375 \mathrm{~m})$ & $14 \mathrm{veh}$. & $225.8 \mathrm{sec} . / \mathrm{veh}$. & $12.6 \mathrm{sec} . / \mathrm{veh}$. \\
\hline Enhanced ATIS $(375 \mathrm{~m})$ & $27 \mathrm{veh}$. & $358.2 \mathrm{sec} . / \mathrm{veh}$. & $37.9 \mathrm{sec} / \mathrm{veh}$. \\
\hline Basic ATIS $(625 \mathrm{~m})$ & $25 \mathrm{veh}$. & $268.7 \mathrm{sec} . / \mathrm{veh}$. & $25.8 \mathrm{sec} . / \mathrm{veh}$. \\
\hline Enhanced ATIS $(625 \mathrm{~m})$ & $34 \mathrm{veh}$. & $367.8 \mathrm{sec} . / \mathrm{veh}$. & $48.1 \mathrm{sec} . / \mathrm{veh}$. \\
\hline
\end{tabular}

Note: (1) number of re-routing vehicles due to traffic incident, (2) average travel time savings of incident-involved participating vehicles, (3) average travel time savings of all participating vehicles

Autonomous Automatic Incident Detection (AAID) is incorporated into the Basic ATIS Model. AAID allows for an earlier identification of the incident. However, the $375 \mathrm{~m}$ radio range is not sufficiently large for a vehicle in the incident-related queue to communicate directly with vehicles upstream the route diverting point, requiring message hops to transmit the message, creating some delay between the issuing of the alert message and the re-routing of participating vehicles to the non-incident route. However, the incident message arrives sooner than in Basic ATIS model, allowing additional participating vehicles to re-route and avoid the incident. For the Basic ATIS Model at the larger radio range of $625 \mathrm{~m}$ in <Fig. 3> (c) participating vehicles start re-routing earlier than in the $375 \mathrm{~m}$ radio range of the Basic ATIS Model, but do not achieve the re-routing benefits achieved when AAID was incorporated, even under the shorter radio range of $375 \mathrm{~m}$. <Fig. 3> (d) depicts re-routing result of the Basic ATIS Model with AAID with the larger radio range $625 \mathrm{~m}$, showing the best performance overall, with the earliest re-routing after incident occurrence. It is readily seen that early detection of incidents allows the ATIS to inform participating vehicles of congestion more quickly and enable more vehicles to bypass the congestion area, which results in more vehicle re-routings and travel time savings, verified by $<$ Table $1>$.

Clearly, the efficiency of ATIS model using V2V communication (travel time savings in <Fig. 3> and $<$ Table 1>) is dependent on how quickly the non-recurrent traffic state can be detected and transmitted to vehicles that have alternate routes available. Therefore, the speed of detection of changing traffic states is a significant factor affecting the efficiency of ATIS using V2V communication.

\section{Conclusions}

This paper discusses the development of a dynamic decentralized ATIS using V2V communication. Three system modules (i.e., wireless communication, on-board database management, and dynamic re-routing) were directly integrated into an off-the-shelf microscopic simulation model, VISSIM and VISSIM COM, and a complementary function (AAID) to improve the system efficiency was implemented in the developed ATIS model. Saved travel time of participating and non-participating vehicles of the ATIS configurations was investigated on a simple experimental traffic network with a traffic incident, assuming an ideal communication environment with no signal interference and no data loss during the communication process.

It has been shown that the rate of detection of a non-recurrent traffic state with AAID is a critical component to the system efficiency for implementing dynamic traffic assignment (DTA) strategy in the decentralized fashion. However, future research is required to better explore potential communication issues, such as message drops, message contention, dissemination methods, etc. Finally, it is required to 
compare the measurement of effectiveness (MOE) like timeliness and accuracy of traffic alert warning system between the existing centralized traffic information system (i.e., automatic incident detection algorithm, AID) and decentralized one (i.e., AAID) proposed in this paper on a larger and more complicated traffic network, representing a more realistic set of route choices and incorporating the potential of alternate route congestion due to route switching.

\section{References}

[1] U.S. DOT, "Connected Vehicle Research," Research and Innovative Technology Administration (RITA), http://www.its.dot.gov/connected_vehicle/connected_ vehicle.htm, Accessed on October 28, 2011.

[2] T. Strang and M. Rockl, "Vehicle Networks-V2X communication protocols," DLR, Netherlands, 2009.

[3] M. Ben-Akiva, M. Bierlaire, H. Koutsopoulos, and R. Mishalani, "DynaMIT: a simulation-based system for traffic prediction," Proceedings of DACCORD Short-term Forecasting Workshop, Delft, Netherlands, 1998.

[4] H. S. Mahmassani, "Dynamic network traffic assignment and simulation methodology for advanced system management applications," Networks and Spatial Economics, vol. 1, no. 3, pp.267-292, 2001.

[5] Y. E. Hawas and H. S. Mahmassani, "Comparative analysis of robustness of centralized and distributed network route control systems in incident situations," Transportation Research Record: Journal of Transportation Research Board, vol. 1537, pp.83-90, 1991.

[6] Y. C. Chiu and H. S. Mahmassani, "Hybrid real-time dynamic traffic assignment approach for robust network performance," Transportation Research Record: Journal of Transportation Research Board, vol. 1783, pp.89-97, 2002.

[7] Y. C. Chiu and H. S. Mahmassani, "Routing profile updating strategies for online hybrid dynamic traffic assignment operation," Transportation Research Record: Journal of Transportation Research Board, vol. 1857, pp.39-47, 2003.

[8] S. Eichler, B. Ostermaier, C. Schroth and T. Kosch, "Simulation of car-to-car messaging: analyzing the impact on road traffic," Proceedings of 13th IEEE International Symposium on Modeling, Analysis, and Simulation of Computer and Telecommunication Systems (MASCOS), Atlanta, GA, 2005.

[9] D. R. Choffnes and F. E. Bustamante, "An integrated mobility and traffic model for vehicular wireless networks," Proceedings of 2nd ACM International Workshop on Vehicular Ad Hoc Networks, Cologne, Germany, 2006.

[10] X. Yang and W. W. Recker, "Modeling dynamic vehicle navigation in a self-organizing, peer-to-peer, distributed traffic information system," Journal of Intelligent Transportation Systems, vol. 10, no. 4, pp.185-204, 2006.

[11] H. Wu, R. M. Fujimoto and G. Riley, "Analytical models for information propagation in vehicle-tovehicle networks," IEEE Transactions on Vehicular Technology, vol. 58, no. 1, IEEE, pp.4548-4552, 2004.

[12] H. S. Mahmassani and P. S. Chen, "Comparative assessment of origin-based and en route real-time information under alternative user behavior rules," Transportation Research Record: Journal of Transportation Research Board, vol. 1306, pp.69-81, 1991.

[13] 김회경, "Development and evaluation of advanced framework of ATIS model," 교통연구, 제 18 권, 제 1호, 한국교통연구원, pp.75-88, 2011.

[14] 김회경, "Development and comparison of centralized and decentralized ATIS models with simulation method," 한국ITS학회논문지, 제 10 권, 제 2 호, 한 국ITS학회, pp.1-8, 2011. 
[15] 김회경, “시뮬레이션기법을 통한 차량 간 통신을 이용한 첨단교통정보시스템의 효과 분석 (도시 도로망을 중심으로)," 대한교통학회지, 제29권, 제5호, pp.121-138, 2011.

[16] H. K. Kim, M. P. Hunter and R. M. Fujimoto, "A simulation-based investigation of a dynamic advanced traveler information system," Proceedings of 2009 Winter Simulation Conference, Austin, TX, 2009.

[17] PTV, "VISSIM 5.10 User Manual," Karlsruhe, Germany, Planung Transport Verkehr (PTV) AG, 2009.

[18] PTV, "VISSIM 5.10 COM Interface Manual,"
Karlsruhe, Germany, Planung Transport Verkehr (PTV) AG, 2009.

[19] H. Wu, J. Lee, M. P. Hunter, R. M. Fujimoto, R. L. Guensler and J. Ko, "Efficiency of simulated vehicle-to-vehicle message propagation in Atlanta, Georgia, I-75 Corridor," Transportation Research Record: Journal of Transportation Research Board, vol. 1910, pp.82-89, 2005.

[20] A. Guin, "An Incident Detection Algorithm Based on a Discrete State Propagation Model of Traffic Flow," Ph.D. Dissertation in Civil Engineering, Georgia Institute of Technology, 2004.

\section{저자소개}

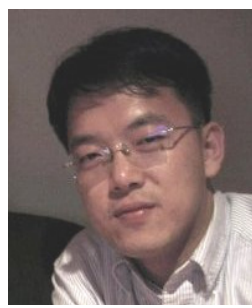

김 회 경 (Kim, Hoe Kyoung)

2010년 2월 2011년 8월 : Post Doctorate Researcher, Oak Ridge National Laboratory, Oak Ridge, Tennessee, USA

2010년 5월 : Georgia Institute of Technology, 공학박사

2003년 12월 : Georgia Institute of Technology, 공학석사

2002년 5월 : Texas A\&M University, 공학석사

2011년 9월 현 재 : 동아대학교 도시계획학과, 조교수 